\title{
Relato de caso: Caracterização físico-química e aceitabilidade de paçoca produzida com amêndoa de castanha-de-caju e sua comparação com produtos comerciais
}

\author{
Case-report: Characterization and acceptability of cashew nut candy and its \\ comparison with commercial products
}

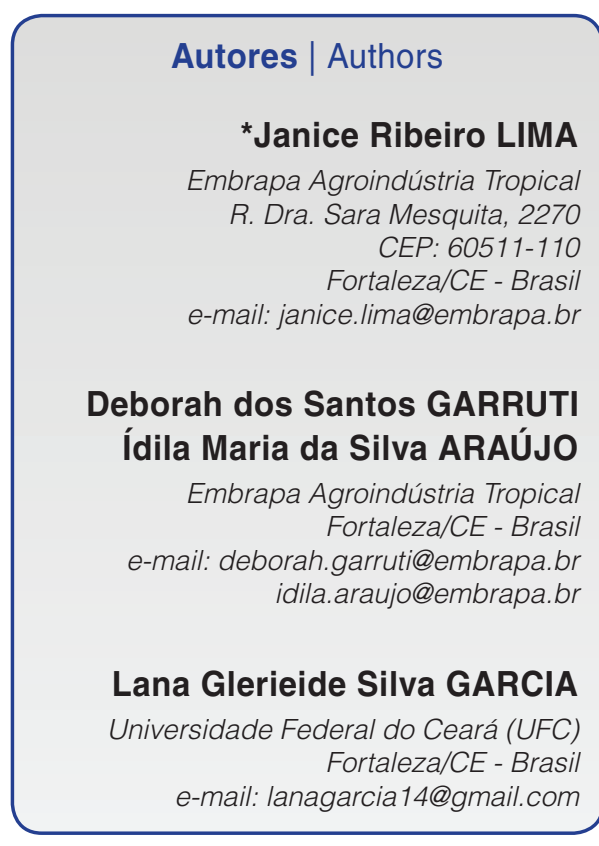

*Autor Correspondente / Corresponding Author Recebido: Set. 03, 2015 Aprovado: Jan. 26, 2016

\section{Resumo}

Este trabalho teve como objetivo comparar as características físico-químicas e a aceitabilidade de um doce tipo paçoca, elaborado a partir de torta de amêndoa de castanha-de-caju com dois produtos similares comerciais de amendoim. A paçoca foi preparada com 59,5\% de torta, 25,0\% de açúcar, 0,5\% de sal, $5,0 \%$ de farinha de mandioca e 10,0\% de óleo de milho, sendo moídos juntos e moldados em forma de paralelepípedo. Os produtos foram analisados para determinação de características físico-químicas (umidade, cinzas, lipídeos, proteínas, carboidratos, atividade de água), cor instrumental ( $\left.L^{*} a^{*} b^{*}\right)$ e aceitação sensorial (escala hedônica de 9 pontos). Os resultados foram comparados por ANOVA e Teste de Tukey $(\alpha=0,05)$. Pequenas diferenças físico-químicas foram observadas: a umidade variou de 1,01 a 2,79\%; cinzas, de 1,23 a 2,75\%; lipídeos, de 30,28 a 31,27\%; proteínas, de 14,19 a 16,90\%; carboidratos, de 50,21 a 54,07\%, e atividade de água, de 0,295 a 0,429. Apesar de a paçoca de amêndoa de castanha-de-caju ser mais clara e menos vermelha $\left(L^{*}=74,48, a^{*}=1,38\right)$ que as comerciais de amendoim (valores médios $L^{*}=54,33, a^{*}=8,08$ ), apresentou aceitação semelhante à desses produtos, que variaram entre 7,0 e 7,8 ("gostei" a "gostei muito" da escala hedônica). Considerando-se a atividade de água inferior a 0,6, a paçoca de torta de amêndoa de castanha-de-caju pode ser considerada microbiologicamente estável à temperatura ambiente, sendo uma boa alternativa para a utilização do subproduto da extração do óleo de amêndoas quebradas.

Palavras-chave: Anacardium occidentale L.; Composição centesimal; Resíduos; Análise sensorial.

\section{Summary}

This work aimed to compare the physicochemical characteristics and acceptance of a cashew nut meal candy with two similar commercial products made from peanut. The candy was prepared using 59.5\% cashew nut meal, $25.0 \%$ sugar, $0.5 \%$ salt, $5.0 \%$ cassava flour and $10.0 \%$ corn oil ground together and moulded into a parallelepiped shape. The products were analysed for their physicochemical characteristics (moisture, ash, lipids, proteins, carbohydrates, water activity), instrumental colour $\left(L^{*} a^{*} b^{*}\right)$ and sensory acceptance ( 9 point hedonic scale). The results were compared by ANOVA and the Tukey's test $(\alpha=0.05)$. Slight physicochemical differences were observed: the moisture content ranged from 1.01 to $2.79 \%$, ash from 1.23 to $2.75 \%$, lipids from 30.28 to $31.27 \%$, proteins from 14.19 to $16.90 \%$, carbohydrates from 50.21 to $54.07 \%$ and water activity from 0.295 to 0.429 . Although the cashew nut candy was lighter and less red $\left(L^{*}=74.48, a^{*}=1.38\right)$ than the commercial peanut candy (mean values $L^{*}=54.33, a^{*}=8.08$ ), it presented similar acceptance to those products, the scores varying between 7.0 and 7.8 ("liked" to "liked very much" on the hedonic scale). Considering that its water activity was lower than 0.6 , the cashew nut candy could be considered microbiological stable at room temperature and could be regarded as a good alternative for the use of the residue obtained after the extraction of oil from broken kernels.

Key words: Anacardium occidentale L.; Proximate composition; Residues; Sensory analysis. 
Relato de caso: Caracterização físico-química e aceitabilidade de paçoca produzida com amêndoa de castanha-de-caju e sua comparação com produtos comerciais

LIMA, J. R. et al.

\section{Introdução}

A paçoca é um doce tradicional no Brasil e possui o amendoim como principal ingrediente, sendo relatada como um produto de alta aceitabilidade (WANG et al., 1999). Além do amendoim, outros ingredientes, como farinha de trigo, fubá, açúcar, mel e gordura, participam de sua formulação, em diferentes proporções. O processamento para a obtenção de paçoca é descrito por Wang et al. (1999) e Ribeiro (2006) como sendo uma homogeneização dos ingredientes, com o amendoim torrado e moído atuando como base das formulações, com posterior moldagem e prensagem.

Por sua vez, o processo de extração de óleo de amêndoa de castanha-de-caju (ACC) tem sido estimulado como forma de aumentar o valor econômico de amêndoas quebradas, que chegam a ser $40 \%$ do total obtido no seu beneficiamento (LIMA et al., 2012a). Ademais, a extração do óleo das amêndoas gera como subproduto uma torta com alto valor nutricional, que pode ser utilizada na elaboração de novos produtos. Aroyeun (2009) reportou valores de composição para torta de ACC de $5,40 \%$ de umidade, $2,60 \%$ de cinzas, $4,10 \%$ de lipídeos, 39,90\% de proteínas e 12,25\% de carboidratos. Freitas e Naves (2010) relataram que o perfil de aminoácidos e a qualidade proteica de nozes e sementes comestíveis atendem à grande parte das necessidades de escolares e adultos. Segundo esses autores, o perfil de aminoácidos essenciais de castanha de caju, em mg/g de proteína, é de 26,8 de histina, 41,5 de isoleucina, 80,0 de leucina, 45,9 de lisina, 28,1 de metionina+cisteína, 72,6 de fenilalanina+tirosina, 32,2 de treonina, 13,1 de triptofano e 56,5 de valina, enquanto que o amendoim é de 25,4 de histina, 34,5 de isoleucina, 70,3 de leucina, 38,8 de lisina, 16,4 de metionina+cisteína, 87,8 de fenilalanina+tirosina, 22,1 de treonina, 7,3 de triptofano e 39,5 de valina.

A elaboração de paçoca com base na torta de ACC, em substituição ao amendoim, é uma alternativa para utilização do subproduto da extração do óleo. Aroyeun (2009) estudou a incorporação de torta de ACC em biscoitos tipo cookie, obtendo boa aceitabilidade sensorial com até $25 \%$ de inclusão.

Neste trabalho, descrevem-se as características físico-químicas e a aceitabilidade sensorial de doce tipo paçoca à base de torta de amêndoa de castanha-de-caju, comparando-o com produtos comerciais à base de amendoim.

\section{Material e métodos}

\subsection{Elaboração da paçoca de amêndoa de castanha-de-caju}

Para elaboração da paçoca, seguiram-se as recomendações descritas por Lima et al. (2012b), sendo a formulação composta de torta de ACC (59,5\%), açúcar $(25,0 \%)$, sal $(0,5 \%)$, farinha de mandioca $(5,0 \%)$ e óleo de milho (10,0\%). A torta de ACC foi obtida como subproduto da extração do óleo, realizada em prensa MA098/50A/1 (Marconi, Piracicaba, Brasil), a $70{ }^{\circ} \mathrm{C}$ e $100 \mathrm{kgf} / \mathrm{cm}^{2}$. As amêndoas foram obtidas no campo experimental da Embrapa, em Pacajus-CE, secas a $100^{\circ} \mathrm{C}$ por 60 minutos e moídas em processador com lâminas de aço inox tipo faca (Robot Coupe R201 Ultra E, Jackson, MS, USA), por aproximadamente dois minutos antes da prensagem. Os demais ingredientes foram adquiridos no mercado local de Fortaleza-CE.

A torta foi previamente torrada a $100{ }^{\circ} \mathrm{C}$ por 90 minutos e os ingredientes foram homogeneizados em processador com lâminas de aço inox tipo faca (Robot Coupe R201 Ultra E, Jackson, MS, USA), por aproximadamente cinco minutos, até a obtenção de uma massa homogênea. A massa obtida foi prensada manualmente em formas de aço inox e cortada em paralelepípedos de aproximadamente $10 \mathrm{~g}$. As paçocas foram então acondicionadas em potes de polipropileno vedados com selos feitos de alumínio e polietileno, mantidos tampados até o momento das análises.

Para efeito de comparação, paçocas à base de amendoim, também chamadas de paçoquinha ou doce de amendoim tipo paçoquinha, de duas marcas comerciais foram adquiridas no mercado local (Tabela 1).

\subsection{Análises físico-químicas}

Na paçoca obtida a partir da torta de ACC e nas paçocas comerciais, foram determinados os seguintes parâmetros: umidade, cinzas, lipídeos totais, proteínas e carboidratos totais (por diferença, em base seca) (IAL, 2008). Para o cálculo do valor energético total,

Tabela 1. Características dos produtos comerciais avaliados.

\begin{tabular}{lcc} 
& Amostra comercial X & Amostra comercial Y \\
Descrição & Paçoquinha de amendoim & Doce de amendoim tipo paçoquinha \\
Formato & Rolha & Paralelepípedo \\
Peso unitário $(\mathrm{g})$ & 22 & 15 \\
Validade (meses) & 6 & 7 \\
Ingredientes & Amendoim, açúcar, fécula de mandioca, & Amendoim torrado e moído, açúcar, sal \\
& farinha de mandioca, sal & \\
\hline
\end{tabular}


Relato de caso: Caracterização físico-química e aceitabilidade de paçoca produzida com amêndoa de castanha-de-caju e sua comparação com produtos comerciais

LIMA, J. R. et al.

utilizaram-se os fatores de conversão de $4 \mathrm{kcal} / \mathrm{g}$ para carboidratos e proteínas e $9 \mathrm{kcal} / \mathrm{g}$ para lipídeos (MERRIL; WATT, 1973). As análises físico-químicas foram realizadas em triplicata. Foi ainda determinada a atividade de água $\left(30 \pm 1^{\circ} \mathrm{C}\right)$, em equipamento Aqualab Decagon CX-2 (Decagon Devices, USA).

A cor das amostras foi analisada usando colorímetro (Chroma Meter CR-400, Konica Minolta Sensing Inc., Osaka, Japão) e o Sistema CIELab, que fornece as coordenadas cartesianas em um espaço tridimensional, em que:

- L* é o eixo y e quantifica a luminosidade, variando de zero (preto) a 100 (branco);

- $a^{*}$ posiciona a cor no eixo x, que varia do verde (valores de -60 a 0 ) ao vermelho (valores de 0 a 60);

b* posiciona a cor no eixo z, que varia do azul (valores de -60 a 0) ao amarelo (valores de 0 a 60).

Com esses valores, também foi calculada a diferença total de cor $\Delta \mathrm{E}^{*}$, entre o produto desenvolvido neste trabalho e as amostras comerciais, pela fórmula:

$\Delta \mathrm{E}^{*}=\left[\left(\Delta \mathrm{L}^{*}\right)^{2}+\left(\Delta \mathrm{a}^{*}\right)^{2}+\left(\Delta \mathrm{b}^{*}\right)^{2}\right]^{1 / 2}$

\subsection{Aceitabilidade sensorial}

Foi realizado teste de aceitação sensorial (MEILGAARD et al., 1999) com 50 provadores, os quais foram solicitados a indicar o quanto gostaram das paçocas utilizando uma escala hedônica estruturada de 9 pontos, variando de 1 (desgostei muitíssimo) a 9 (gostei muitíssimo). Os testes foram realizados em cabines individuais com iluminação branca, tipo luz do dia. As amostras foram servidas em pratos descartáveis brancos, codificados com números aleatórios de três dígitos, e apresentadas de forma monádica e balanceada (MCFIE et al., 1989), para minimizar o efeito de posição das amostras. Um copo de água foi oferecido entre as amostras, para eliminar o sabor residual na boca. Os protocolos dos testes sensoriais foram previamente aprovados pelo Comitê de Ética em Pesquisa da Universidade Estadual do Ceará, parecer n. ${ }^{\circ} 147.279$.

\subsection{Análise estatística}

Os resultados foram avaliados por Análise de Variância e as médias foram comparadas pelo Teste de Tukey $(\alpha=0,05)$, usando-se o programa SAS para Windows (SAS INSTITUTE, 2009).

\section{Resultados e discussão}

As composições centesimais da paçoca elaborada com torta de ACC e das paçocas comerciais de amendoim são apresentadas na Tabela 2.

A paçoca de torta de ACC apresentou valores de umidade e cinzas superiores aos das paçocas comerciais, de amendoim. O maior teor de umidade da paçoca de ACC pode ser devido ao tempo de exposição ao ambiente com alta umidade relativa ( $80 \%)$, antes da embalagem, já que o processo foi manual e lento. Apesar de conter farinha de mandioca na sua formulação, apresentou, ainda, teor de proteínas superior e de carboidratos inferior à amostra comercial X, elaborada com adição de fécula e farinha de mandioca. Os valores para lipídeos não se diferenciaram entre as amostras avaliadas. Apesar das diferenças observadas na umidade, todas as amostras tiveram baixa atividade de água $(<0,5)$, o que permite sua comercialização e armazenamento à temperatura ambiente, já que, nesses valores, não ocorre desenvolvimento de microrganismos (TROLLER, 1980).

Os valores energéticos totais foram altos para todas as amostras, sendo que a paçoca comercial Y, elaborada somente com amendoim, e a elaborada com a torta de ACC apresentaram valores superiores ao da paçoca comercial X. No entanto, se considerarmos uma porção unitária do doce de $20 \mathrm{~g}$ e a ingestão recomendada de $2000 \mathrm{kcal}$ ao dia (BRASIL, 2003), a paçoca de

Tabela 2. Composição centesimal, valor energético total e atividade de água de paçoca de torta de amêndoa de castanha-de-caju e de paçocas comerciais de amendoim (média \pm desvio padrão).

\begin{tabular}{|c|c|c|c|}
\hline ANÁLISES & Amostra comercial $\mathrm{X}$ & Amostra comercial Y & $\begin{array}{l}\text { Paçoca de torta } \\
\text { de amêndoa de } \\
\text { castanha-de-caju }\end{array}$ \\
\hline Umidade (\%) & $1,85 \pm 0,02 b$ & $1,01 \pm 0,02 \mathrm{c}$ & $2,79 \pm 0,09 a$ \\
\hline Cinzas (\%, bs) & $1,23 \pm 0,02^{c}$ & $1,62 \pm 0,03^{b}$ & $2,75 \pm 0,04^{a}$ \\
\hline Lipídeos totais (\%, bs) & $30,51 \pm 0,59 a$ & $31,27 \pm 1,18^{a}$ & $30,28 \pm 0,22{ }^{a}$ \\
\hline Proteínas $(\mathrm{N}$ x 6,25) (\%, bs) & $14,19 \pm 0,17 b$ & $16,90 \pm 0,16^{a}$ & $16,59 \pm 0,23^{a}$ \\
\hline Carboidratos totais (\%, bs) & $54,07 \pm 0,59 a$ & $50,21 \pm 1,12^{b}$ & $50,38 \pm 0,48 b$ \\
\hline Valor energético total (kcal/100g) & $486,6 \pm 1,78 b$ & $549,9 \pm 6,02$ a & $540,4 \pm 0,95^{a}$ \\
\hline Atividade de água & $0,429 \pm 0,000^{a}$ & $0,295 \pm 0,003^{b}$ & $0,425 \pm 0,006^{a}$ \\
\hline
\end{tabular}

bs: base seca. Em cada linha, médias seguidas de mesmas letras não são significativamente diferentes (Tukey, $\alpha=0,05)$. 
Relato de caso: Caracterização físico-química e aceitabilidade de paçoca produzida com amêndoa de castanha-de-caju e sua comparação com produtos comerciais

LIMA, J. R. et al.

Tabela 3. Cor de paçoca de torta de amêndoa de castanha-de-caju e de paçocas comerciais de amendoim (média \pm desvio padrão).

\begin{tabular}{lccc}
\multicolumn{1}{c}{ Cor } & Amostra comercial X & Amostra comercial Y & $\begin{array}{c}\text { Paçoca de torta de amêndoa } \\
\text { de castanha-de-caju }\end{array}$ \\
\hline$L^{*}$ (preto-branco) & $53,40 \pm 1,10^{\mathrm{b}}$ & $55,26 \pm 0,30^{\mathrm{b}}$ & $74,48 \pm 0,37^{\mathrm{a}}$ \\
$\mathrm{a}^{*}$ (verde-vermelho) & $7,88 \pm 0,23^{\mathrm{a}}$ & $8,28 \pm 0,13^{\mathrm{a}}$ & $1,38 \pm 0,09 \mathrm{~b}$ \\
$\mathrm{~b}^{*}$ (azul-amarelo) & $21,84 \pm 0,21^{\mathrm{b}}$ & $23,19 \pm 0,08^{\mathrm{a}}$ & $21,85 \pm 0,09 \mathrm{~b}$ \\
$\Delta \mathrm{E}^{*}$ & 22,05 & 20,46 & -- \\
\hline
\end{tabular}

Em cada linha, médias seguidas de mesmas letras não são significativamente diferentes (Tukey, $\alpha=0,05)$. $\Delta \mathrm{E}^{\star}$ foi calculado a partir das médias.

Tabela 4. Aceitação sensorial de paçoca de torta de amêndoa de castanha-de-caju e de paçocas comerciais de amendoim (média \pm desvio padrão)

\begin{tabular}{lccc} 
& Amostra comercial X & Amostra comercial Y & $\begin{array}{c}\text { Paçoca de torta de amêndoa } \\
\text { de castanha-de-caju }\end{array}$ \\
\hline $\begin{array}{l}\text { Valor hedônico (escala de } \\
9 \text { pontos) }\end{array}$ & $7,0 \pm 1,6^{b}$ & $7,8 \pm 1^{\mathrm{b}}$ a $^{\mathrm{a}}$ & $7,3 \pm 1,6^{\mathrm{ab}}$ \\
\hline
\end{tabular}

Médias seguidas de mesmas letras não são significativamente diferentes (Tukey, $\alpha=0,05$ ).

torta de ACC teria valor energético de $108 \mathrm{kcal}$, o que corresponderia a apenas $5,4 \%$ das calorias diárias recomendadas.

Outros autores trabalharam com elaboração de paçocas a partir de materiais alternativos ao amendoim. Santos et al. (2012) testaram elaboração de paçocas com amêndoa de baru e amendoim, nas proporções de 75:25, 50:50 e 25:75, e encontraram composição com valores semelhantes de proteínas (13,53 a 16,72\%), mas valores inferiores de lipídeos (17,81 a 19,45\%) e carboidratos (43,16 a 44,73\%), em relação à paçoca deste estudo, elaborada com torta de ACC. Wang et al. (1999) testaram a utilização de resíduo do leite de soja na elaboração de paçoca. As seis formulações testadas tinham concentrações fixas de 22,0 g de açúcar, 8,0 g de margarina e 40,0 g de farinha de trigo em 100,0 g do produto, sendo os 30,0 g restantes de proporções diferentes de amendoim e resíduo do leite de soja. Os produtos finais apresentaram aproximadamente 6,00\% de umidade, $15,00 \%$ de proteína, 11,00 a 19,00\% de lipídeos e 56,06 a 61,40\% de carboidratos, ou seja, valores semelhantes de proteínas, mas inferiores de lipídeos e superiores de carboidratos, quando comparados aos valores da paçoca elaborada com torta de ACC.

Ribeiro (2006) também avaliou a utilização do resíduo do extrato de soja na formulação de paçoca. Cinco formulações foram testadas com concentrações fixas de 35,0 $\mathrm{g}$ de amendoim, 0,5 $\mathrm{g}$ de sal e 24,5 $\mathrm{g}$ de melado de cana em 100,0 g de produto, sendo os $40 \mathrm{~g}$ restantes de proporções diferentes de resíduo do extrato de soja e fubá. Os produtos apresentaram teores de umidade de 10,00 a 15,00\%, proteína de 16,00 a 31,00\% e lipídeos de 18,00 a 25,00\%, ou seja, valores semelhantes de proteínas, mas inferiores de lipídeos e superiores de umidade, em relação aos valores da paçoca elaborada com torta de ACC.
Com relação à cor, observou-se que a paçoca de torta de ACC apresentou-se muito diferente das amostras comerciais de amendoim, visto que o $\Delta \mathrm{E}^{*}$ ficou muito acima de 5,0, valor acima do qual, segundo Mokrzycki e Tatol (2011), um observador não treinado já percebe duas cores diferentes. A paçoca de ACC ficou mais clara ( $L^{*}$ maior) e menos avermelhada ( $a^{*}$ menor) que as paçocas comerciais de amendoim (Tabela 3 ). Isso era esperado, pois a amêndoa de castanha-de-caju é muito clara e, mesmo torrada, não apresenta a coloração avermelhada do amendoim.

A paçoca de torta de ACC apresentou aceitação sensorial semelhante à das paçocas comerciais (Tabela 4), com valor hedônico médio de 7,3, que corresponde, na escala hedônica, a avaliações entre "gostei" e "gostei muito". Valores semelhantes foram relatados por Wang et al. (1999) para paçoca elaborada com resíduo da extração de leite de soja, com valores de aceitação para aparência, sabor e textura em torno de 8,0, e por Santos et al. (2012), para paçoca com 50\% de substituição do amendoim por baru, com aceitação global de 7,3; observe que, em ambos os estudos, os autores também utilizaram escala hedônica de 9 pontos. No entanto, o valor de aceitação encontrado para paçoca de torta de ACC foi superior ao encontrado por Ribeiro (2006) para paçoca elaborada com resíduo da extração do leite de soja, que apresentou valores para aceitação sensorial global variando de 5,0 a 6,5 (escala de 9 pontos).

\section{Conclusão}

A composição centesimal da paçoca elaborada à base de torta de amêndoa de castanha-de-caju apresentou diferenças em relação às paçocas comerciais de amendoim, sendo, também, mais clara e menos avermelhada que as comerciais de amendoim. No entanto, 
Relato de caso: Caracterização físico-química e aceitabilidade de paçoca produzida com amêndoa de castanha-de-caju e sua comparação com produtos comerciais

LIMA, J. R. et al.

apesar dessas diferenças, o produto foi bem aceito, em nível semelhante aos dos produtos comerciais, indicando que a elaboração do doce tipo paçoca com torta de amêndoa de castanha-de-caju é uma alternativa para utilização do subproduto da extração do óleo de amêndoas quebradas.

\section{Referências}

AROYEUN, S. O. Utilization of cashew kernel meals in the nutritional enrichment of biscuit. African Journal of Food Science, Lagos, v. 3, n. 10, p. 316-319, 2009.

BRASIL. Ministério da Saúde. Agência Nacional de Vigilância Sanitária. Resolução RDC n³59, de 23 de dezembro de 2003. Regulamento Técnico de porções de alimentos embalados para fins de rotulagem nutricional. Diário Oficial [da] República Federativa do Brasil, Brasília, DF, 26 dez. 2003. Disponível em: <http://portal.anvisa.gov.br/wps/wcm/connect/d12c9e80 4745947f9bf0df3fbc4c6735/RDC_359.pdf?MOD=AJPERES $>$. Acesso em: 27 jul. 2015.

FREITAS, J. B.; NAVES, M. M. V. Composição química de nozes e sementes comestíveis e sua relação com a nutrição e saúde. Revista de Nutrição, Campinas, v. 23, n. 2, p. 269-279, 2010.

INSTITUTO ADOLFO LUTZ - IAL. Normas analíticas do Instituto Adolfo Lutz: métodos físico-químicos para análise de alimentos. São Paulo: Instituto Adolfo Lutz, 2008. 1020 p.

LIMA, J. R.; GARRUTI, D. S.; BRUNO, L. M. Physicochemical, microbiological and sensory characteristics of cashew nut butter made from different kernel grades-quality. LWT - Food Science and Technology, Zurich, v. 45, n. 2, p. 180-185, 2012a.

LIMA, J. R.; GARRUTI, D. S.; BRUNO, L. M.; ARAÚJO, I. M. S.; NOBRE, A. C. O.; GARCIA, L. G. S. Elaboração de doce tipo paçoca a partir do resíduo da extração do óleo de amêndoa de castanha-de-caju. Fortaleza: Embrapa, 2012b. (Comunicado técnico, 189).
MCFIE, H. J.; BRATCHELL, N.; GREENHOFF, K.; VALLIS, L. $\mathrm{V}$. Designs to balance the effect of order of presentation and first-order carry-over effects in hall tests. Journal of Sensory Studies, Westport, v. 4, n. 2, p. 129-148, 1989. http://dx.doi. org/10.1111/j.1745-459X.1989.tb00463.x.

MEILGAARD, M.; CIVILLE, G. V.; CARR, B. T. Sensory evaluation techniques. 3. ed. New York: CRC Press, 1999.

MERRIL, A. L.; WATT, B. K. Energy value of foods: basis and derivation. Washington, DC: United States Department of Agriculture, 1973. (Agriculture handbook, 74).

MOKRZYCKI, W.; TATOL, M. Color difference Delta E: a survey. Machine Graphics and Vision, Warszawa, v. 20, n. 4, p. 383-411, 2011. Disponível em: <http://www.researchgate.net/ publication/236023905_Color_difference_Delta_E_-_A_survey $>$. Acesso em: 03 ago. 2015.

RIBEIRO, V. A. Aproveitamento do resíduo do extrato de soja na elaboração de um produto tipo paçoca. 2006. $75 \mathrm{f}$. Dissertação (Mestrado Ciência dos Alimentos)-Universidade Federal de Lavras, Lavras, 2006.

SANTOS, G. G.; SILVA, M. R.; LACERDA, D. B. C. L.; MARTINS, D. M. O.; ALMEIDA, R. A. Aceitabilidade e qualidade físico-química de paçocas elaboradas com amêndoa de baru. Pesquisa Agropecuária Tropical, Goiânia, v. 42, n. 2, p. 159-165, 2012.

SAS INSTITUTE. Statistical analysis system user's guide. Cary: SAS Institute, 2009.

TROLLER, J. A. Influence of water activity on microorganisms in foods. Food Technology, Chicago, v. 34, n. 5, p. 76-80, 1980.

WANG, S. H.; CABRAL, L. C.; BORGES, G. G. Utilização do resíduo do leite de soja na elaboração de paçoca. Pesquisa Agropecuária Brasileira, Brasília, v. 34, n. 7, p. 1305-1311, 1999. 